\title{
Clinical Reasoning: A 71-year-old man receiving treatment for cryptococcal meningitis, developing new-onset lethargy
}

Teng J. Peng, MD, Tara Kimbrough, MD, MPH, and Benjamin D. Tolchin, MD, MS

Neurology ${ }^{\circledR}$ 2019;92:815-820. doi:10.1212/WNL.0000000000007379
Correspondence

Dr. Peng

teng.pengzhao@yale.edu

\section{Section 1}

A 71-year-old man presented to the hospital with low-grade fevers and a headache. Over the course of 2 weeks, he had developed urinary incontinence and worsening blurry vision. The patient had a history of heavy alcohol use but stopped drinking 1 month prior to presentation. The patient was not known to be immunocompromised.

In the emergency department, vitals were remarkable for a fever of $102.4^{\circ} \mathrm{F}$. Basic laboratory studies at that time were within normal limits. Head CT and brain MRI were notable for mild hydrocephalus (figure 1, A-E). A lumbar puncture was performed with opening pressure of 37

Figure $1 \mathrm{CT}$ and MRI scan on admission to hospital

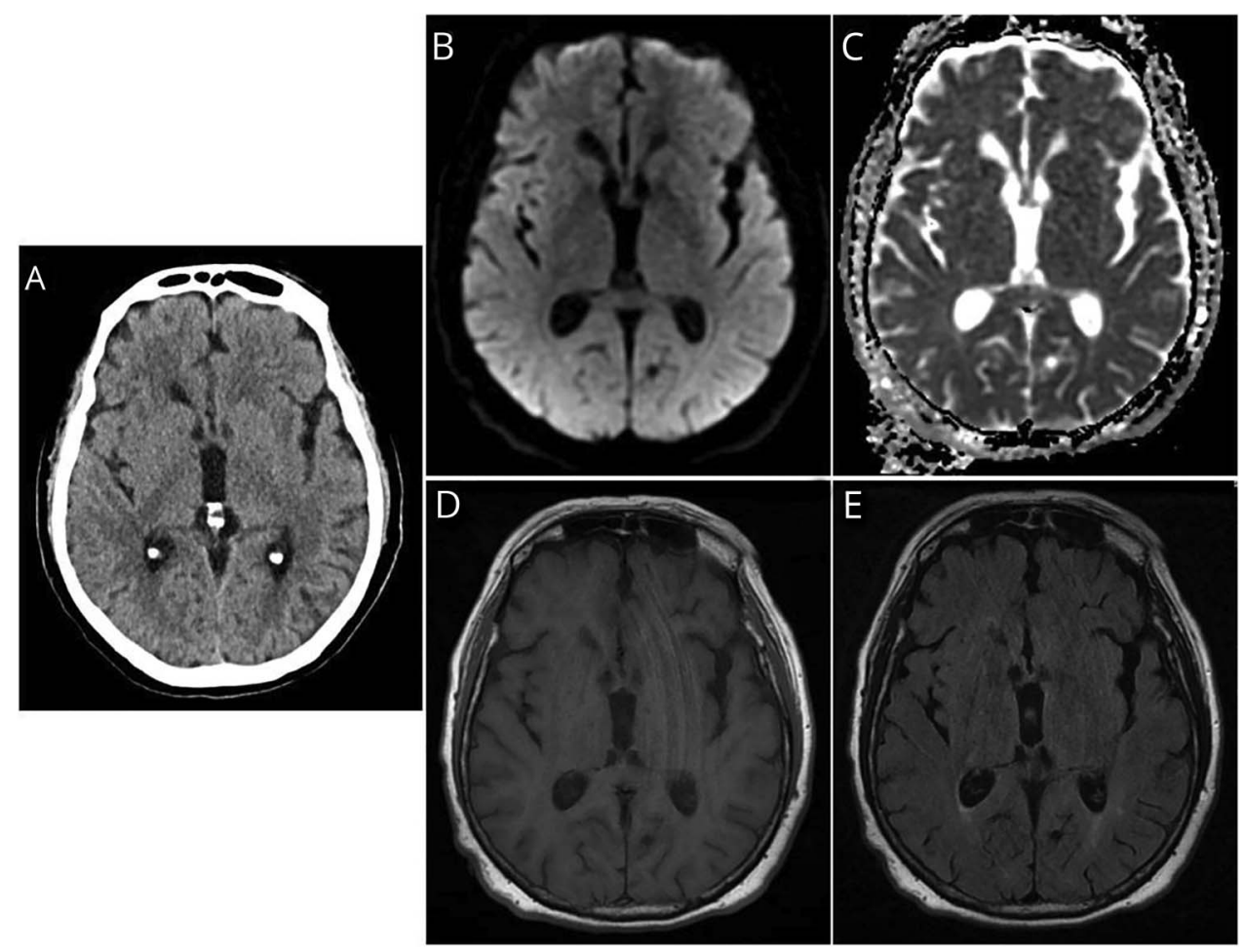

(A) CT scan of head on initial admission to hospital shows mild hydrocephalus. (B) Diffusion-weighted imaging, (C) apparent diffusion coefficient, (D) fluid-attenuated inversion recovery, and (E) T1 sequence of patient prior to decline in mental status.

From the Department of Neurology (T.J.P., T.K., B.D.T.), Yale University School of Medicine, New Haven, CT; and Neurology Service (B.D.T.), VA Connecticut Healthcare System, West Haven.

Go to Neurology.org/N for full disclosures. Funding information and disclosures deemed relevant by the authors, if any, are provided at the end of the article. 
$\mathrm{cm} \mathrm{H}_{2} \mathrm{O}$ and CSF studies revealed glucose of $13 \mathrm{mg} / \mathrm{dL}$, protein of $152 \mathrm{mg} / \mathrm{dL}$, and white blood cell count of 209 cells $/ \mathrm{mm}^{3}$ (4.8\% neutrophils and $95.2 \%$ lymphocytes). CSF Cryptococcus antibody was present at a titer of 1:1,024 and CSF culture later revealed Cryptococcus neoformans. HIV titers were negative. Treatment with serial lumbar punctures and antifungals amphotericin and flucytosine was initiated.

The patient clinically improved with antifungal treatment and serial lumbar punctures, but 10 days later suddenly became somnolent. He could be awakened by noxious stimuli but would fall asleep immediately after external stimuli was withdrawn.
When awake, he was oriented to self and able to follow simple commands, but intermittently disoriented to time and place and lacked insight about his hospitalization. The patient had intact vertical and horizontal occulocephalics, but absent vertical optokinetic nystagmus. Other parts of the neurologic examination were unremarkable. Gait could not be evaluated.

\section{Questions for consideration:}

1. What could be the cause of this patient's new lethargy, despite antifungal treatment?

2. What new or repeat testing would you consider to evaluate the patient's new symptoms?

GO TO SECTION 2 


\section{Section 2}

Some plausible differential diagnoses include the following:

\section{Elevated intracranial pressure (ICP)}

Cryptococcus can commonly cause obstruction of the CSF outflow with elevated ICP, which is typically defined as $>20 \mathrm{~mm} \mathrm{Hg}^{1}{ }^{1}$ Symptoms of increased ICP include headache, nausea, vision changes, and decreased alertness. This is best evaluated and treated with a lumbar puncture.

\section{Seizures}

Seizures can be caused by any inflammatory or infectious process involving the neurocortex including cryptococcal CNS infections. Nonconvulsive seizures can cause lethargy and confusion such as exhibited by our patient, without any clinically apparent motor manifestations. Seizures would not explain his absent vertical optokinetic nystagmus. Nonconvulsive seizures can be evaluated with the use of prolonged video-EEG (vEEG).

\section{Cryptococcomas}

Cryptococcomas are mass lesions caused by Cryptococcus infections. Cryptococcomas are more common in patients with Cryptococcus gattii than in patients with $C$ neoformans infections. ${ }^{2}$ Symptoms of cryptococcomas depend on their location, but can disrupt CSF flow and cause increased ICP with subsequent decreased alertness. Patients with cryptococcomas require prolonged treatment with antifungals but generally have a good prognosis. ${ }^{3}$ This is best evaluated with MRI. Cryptococcomas are hyperintense in fluid-attenuated inversion recovery (FLAIR) and have variable contrast enhancement. ${ }^{4}$

\section{Ischemic vascular disease}

Given the patient's sudden onset of symptoms, ischemic strokes, hemorrhagic strokes, and vasculitis are in the differential. Lesions in the brainstem or bilateral thalamus can impair the reticular activating system (RAS) and cause symptoms of decreased alertness as well as cranial nerve palsies. ${ }^{5}$ This is best evaluated with MRI. We would expect to see restricted diffusion in diffusion-weighted imaging (DWI) and apparent diffusion coefficient $(\mathrm{ADC})$ along with variable FLAIR hyperintensity if the stroke is acute/subacute. We would expect minimal or no contrast enhancement.

\section{Wernicke encephalopathy}

The differential for this patient with history of alcohol use disorder also includes Wernicke encephalopathy, due to

Figure 2 CT and MRI scan 10 days after treatment for cryptococcal meningitis

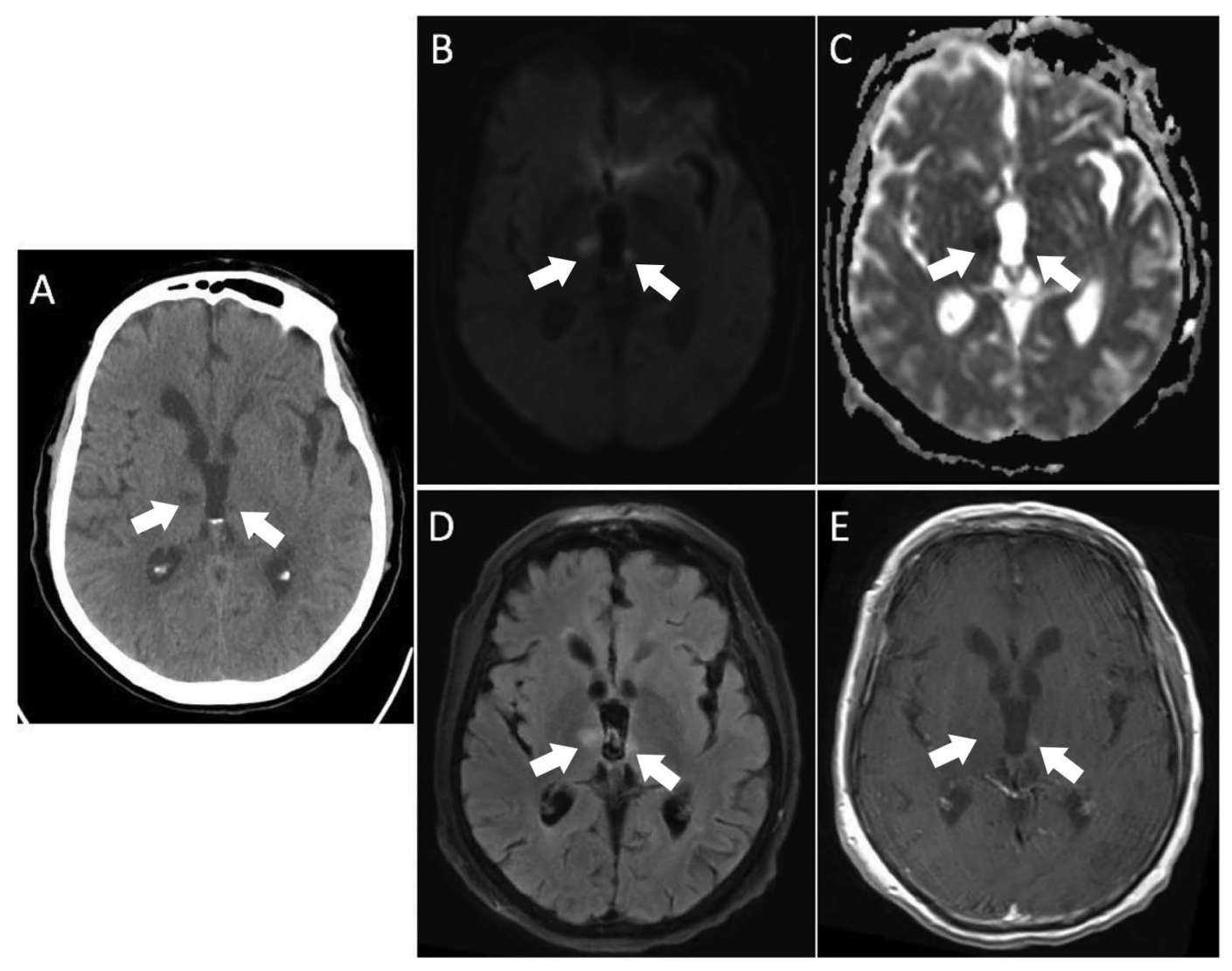

(A) CT scan of the head 10 days after being admitted to hospital for treatment of cryptococcal meningitis. Arrows indicate hypodense bilateral thalamic lesions. (B) Diffusion-weighted imaging shows bilateral thalamic hyperintensities indicative of restricted diffusion. These areas appear hypointense in (C) apparent diffusion coefficient imaging, indicative of acute ischemia. They also appear hyperintense in (D) fluid-attenuated inversion recovery, but do not enhance in (E) postcontrast T1-weighted imaging. 
thiamine deficiency. The clinical manifestations of Wernicke encephalopathy include confusion, ataxia, and ophthalmoplegia. This is best evaluated with MRI, a serum thiamine level, and empiric thiamine repletion. We would typically see symmetric increased signal intensity on FLAIR of the dorsomedial thalamus, mammillary bodies, tectal plate, and periaqueductal area. These lesions classically show restricted diffusion in DWI/ADC and can have contrast enhancement, especially in the mammillary bodies. ${ }^{6}$

Repeat lumbar puncture was performed and CSF results showed an opening pressure of $10 \mathrm{~cm} \mathrm{H}_{2} \mathrm{O}$, glucose of $32 \mathrm{mg} / \mathrm{dL}$, protein of $99.3 \mathrm{mg} / \mathrm{dL}$, white blood cell count of 38 cells $/ \mathrm{mm}^{3}$ (13\% neutrophils and $87 \%$ lymphocytes), and cryptococcus titer of 1:2,560. A prolonged vEEG was performed, which showed generalized slowing but no seizure or epileptiform activity.
These results ruled out the possibility of increased intracranial pressure and markedly decreased the concern for seizures.

A CT scan was performed and showed hypodensities in the bilateral thalamus that were not present on the prior CT scan (figure 2A). The new findings on the CT scan narrow the differential to cryptococcomas, ischemia, or an inflammatory process such as Wernicke encephalopathy. To distinguish between these conditions, a brain MRI with and without contrast was obtained (figure 2, B-E).

\section{Questions for consideration:}

1. How would you interpret the MRI results?

2. What is the most likely cause of the patient's symptoms?

3. What is the next step in treatment or diagnosis? 


\section{Section 3}

The MRI showed areas of restricted diffusion in the bilateral thalamus on DWI with a correlate in ADC imaging. These thalamic lesions also appeared hyperintense on FLAIR imaging but did not enhance with contrast. Overall, the MRI findings and the patient's abrupt onset of clinical symptoms are most consistent with ischemia of the bilateral thalami, which can be due to mechanical obstruction or inflammation. Although these findings could also be consistent with Wernicke encephalopathy, this condition typically involves contrast-enhancing lesions with imaging abnormalities that are not limited exclusively to the thalamus.

For bilateral thalamic strokes to occur from embolic or thrombotic causes, 2 separate interpeduncular branches from the posterior cerebral artery feeding to the thalamus would need to become hypoxic in close temporal proximity. A more likely cause of mechanical obstruction is that the patient has an obstructed artery of Percheron, a normal vascular variant where a single vessel from the posterior cerebral artery supplies both thalami, which may or may not be visualized on vessel imaging. ${ }^{7}$ Inflammatory causes of ischemic vascular disease, such as vasculitis, have also been associated with Cryptococcus. ${ }^{8}$ Regardless of the specific mechanism, bilateral thalamic strokes are notable for causing lethargy, anhedonia, and sleep difficulties and can explain the patient's symptoms. ${ }^{5,9}$

The patient remained in the hospital and underwent a stroke evaluation with an echocardiogram, telemetry monitoring, and CT angiogram of the head and neck vessels; all results were unremarkable. There was low concern for vasculitis due to no evidence of segmental vessel narrowing on vessel imaging and low inflammatory markers (erythrocyte sedimentation rate and $\mathrm{C}$-reactive protein). Given the continued concern for Wernicke encephalopathy, a thiamine level was obtained and found to be low at $<7$, so the patient received treatment with high doses of IV thiamine and folic acid. Other metabolic laboratory studies were within normal limits. For the cryptococcal meningitis, the patient continued treatment with antifungals and received serial lumbar punctures, each showing improvement in ICP and lower cryptococcal titers. Despite completing treatment with IV thiamine and undetectable cryptococcal titers, the patient continued to have absent vertical optokinetic nystagmus and remained hypoactive throughout his hospitalization and at the time of his discharge.

To distinguish between ischemia and Wernicke encephalopathy, which tends to resolve or improve after treatment, an additional MRI was performed 2 weeks after continued treatment with high-dose thiamine. The new MRI findings show stable lesions in the bilateral thalamus and a new tiny focus of restricted diffusion within the left posterior parietal lobe consistent with acute/subacute ischemia. These findings further support the diagnosis of small vessel infarcts secondary to cryptococcal meningitis.

\section{Discussion}

The neurologic manifestations of cryptococcal meningitis in immunocompetent patients typically include fevers and headaches, but can manifest as memory loss, personality changes, and lethargy. The patient described above developed sudden-onset lethargy and further imaging revealed bilateral thalamic strokes.

Besides playing a critical role in the relay of sensory and motor signals, the thalamus also contains elements of the RAS, including the thalamic reticular nuclei and the intralaminar nuclei, and functions in the regulation of alertness and sleep. Bilateral thalamic strokes are rare and often described in patients with occlusions of the artery of Percheron. In such patients, the area of ischemia typically involves the paramedian thalamic territory and the symptoms include altered consciousness (hypersomnia or coma), vertical gaze palsies, and cognitive disturbance. ${ }^{7}$ Based on anatomical and clinical findings, the patient presented in this case report most likely developed an occlusion in the artery of Percheron.

Cryptococcus meningitis has been previously associated with the presence of ischemic lacunar strokes primarily in the basal ganglia, thalamus, and internal capsule. ${ }^{10}$ Given the small size of these strokes, most go undetected. Our patient had normal imaging on admission, then 10 days later was found to have bilateral thalamic ischemic strokes, with a punctate stroke in the posterior parietal lobe being found on subsequent serial imaging. These findings support the hypothesis that Cryptococcus may have an inflammatory effect on CNS microvasculature and encourages the use of neuroimaging when patients with cryptococcal meningitis develop sudden-onset neurologic deficits.

\section{Author contributions}

T.J. Peng: drafting the manuscript, study concept and design, analysis and interpretation of data, acquisition of data. T. Kimbrough: revising the manuscript for content, analysis and interpretation of data. B. Tolchin: revising the manuscript for content, study concept and design, analysis and interpretation of data, study supervision and coordination.

\section{Study funding}

No targeted funding reported.

\section{Disclosure}

T. Peng and T. Kimbrough report no disclosures relevant to the manuscript. B. Tolchin receives research funding from the Veteran's Health Administration VISN1 Career Development Award, the C.G. Swebilius Trust, and the Veteran's Health Administration's Pain Research, Informatics, Multimorbidities, and Education (PRIME) Center of Innovation. Go to Neurology.org/ $\mathrm{N}$ for full disclosures.

\section{References}

1. Graybill JR, Sobel J, Saag M, et al. Diagnosis and management of increased intracranial pressure in patients with AIDS and cryptococcal meningitis: The NIAID Mycoses Study Group and AIDS Cooperative Treatment Groups. Clin Infect Dis 2000;30: $47-54$. 
2. Speed B, Dunt D. Clinical and host differences between infections with the two varieties of Cryptococcus neoformans. Clin Infect Dis 1995;21:28-36; discussion 35-36.

3. Perfect JR, Dismukes WE, Dromer F, et al. Clinical practice guidelines for the management of cryptococcal disease: 2010 update by the Infectious Diseases Society of America. Clin Infect Dis 2010;50:291-322.

4. Loyse A, Moodley A, Rich P, et al. Neurological, visual, and MRI brain scan findings in 87 South African patients with HIV-associated cryptococcal meningoencephalitis. J Infect 2015;70:668-675.

5. Bogousslavsky J, Regli F, Uske A. Thalamic infarcts: clinical syndromes, etiology, and prognosis. Neurology 1988;38:837-848.
6. Zuccoli G, Santa Cruz D, Bertolini M, et al. MR imaging findings in 56 patients with Wernicke encephalopathy: nonalcoholics may differ from alcoholics. AJNR Am J Neuroradiol 2009;30:171-176.

7. Lazzaro NA, Wright B, Castillo M, et al. Artery of Percheron infarction: imaging patterns and clinical spectrum. AJNR Am J Neuroradiol 2010;31:1283-1289.

8. Zimelewicz Oberman D, Patrucco L, Cuello Oderiz C. Central nervous system vasculitis for Cryptococcosis in an immunocompetent patient. Diseases 2018;6:E75.

9. Steinke W, Sacco RL, Mohr JP, et al. Thalamic stroke: presentation and prognosis of infarcts and hemorrhages. Arch Neurol 1992;49:703-710.

10. Mishra AK, Arvind VH, Muliyil D, et al. Cerebrovascular injury in cryptococcal meningitis. Int J Stroke 2018;13:57-65.

\section{Now Accepting Applications for Practice Leadership Program}

Applications are now open for the prestigious Practice Leadership Program, designed to identify and engage solo and small practitioners interested in helping to shape the future of neurology within the American Academy of Neurology and/or their communities. The program's flexible schedule easily accommodates the restricted schedules of busy practitioners. The application deadline is June 17. Learn more and apply at AAN.com/view/PLP.

\section{Share Your Artistic Expressions in Neurology 'Visions'}

AAN members are urged to submit medically or scientifically related artistic images, such as photographs, photomicrographs, and paintings, to the "Visions" section of Neurology ${ }^{\bullet}$. These images are creative in nature, rather than the medically instructive images published in the NeuroImages section. The image or series of up to six images may be black and white or color and must fit into one published journal page. Accompanying description should be 100 words or less; the title should be a maximum of 96 characters including spaces and punctuation.

Please access the Author Center at NPub.org/authors for full submission information.

\section{Disputes \& Debates: Rapid online correspondence}

The editors encourage comments on recent articles through Disputes \& Debates:

Access an article at Neurology.org/N and click on "COMMENT" beneath the article header. Responses will be posted within 3 business days.

Before submitting a comment to Disputes \& Debates, remember the following:

- Disputes \& Debates is restricted to comments about studies published in Neurology within the last eight weeks

- Read previously posted comments; redundant comments will not be posted

- Your submission must be 200 words or less and have a maximum of five references; reference one must be the article on which you are commenting

- You can include a maximum of five authors (including yourself) 


\section{Neurology}

\section{Clinical Reasoning: A 71-year-old man receiving treatment for cryptococcal meningitis, developing new-onset lethargy}

Teng J. Peng, Tara Kimbrough and Benjamin D. Tolchin

Neurology 2019;92;815-820

DOI 10.1212/WNL.0000000000007379

\section{This information is current as of April 22, 2019}

\section{Updated Information \& Services}

References

Subspecialty Collections

Permissions \& Licensing

Reprints including high resolution figures, can be found at: http://n.neurology.org/content/92/17/815.full

This article cites 10 articles, 3 of which you can access for free at: http://n.neurology.org/content/92/17/815.full\#ref-list-1

This article, along with others on similar topics, appears in the following collection(s):

\section{Alcohol}

http://n.neurology.org/cgi/collection/alcohol

All Cerebrovascular disease/Stroke

http://n.neurology.org/cgi/collection/all_cerebrovascular_disease_strok $\mathrm{e}$

\section{Fungal infections}

http://n.neurology.org/cgi/collection/fungal_infections

Information about reproducing this article in parts (figures,tables) or in its entirety can be found online at:

http://www.neurology.org/about/about_the_journal\#permissions

Information about ordering reprints can be found online:

http://n.neurology.org/subscribers/advertise

Neurology ${ }^{\circledR}$ is the official journal of the American Academy of Neurology. Published continuously since 1951, it is now a weekly with 48 issues per year. Copyright @ 2019 American Academy of Neurology. All rights reserved. Print ISSN: 0028-3878. Online ISSN: 1526-632X.

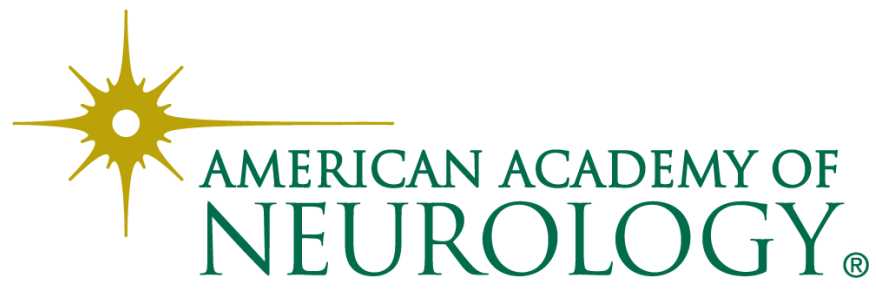

